\title{
Dynamics of Organizational Change
}

\author{
Maximo Flores-Cabezas ${ }^{1}$ \\ Faculty of Accounting, Economic \\ and Financial Sciences \\ Universidad de Ciencias y \\ Humanidades, Lima, Perú
}

\author{
Desiree Flores-Moya ${ }^{2}$ \\ Faculty of Engineering \\ Universidad de Ciencias y \\ Humanidades \\ Lima, Perú
}

\author{
Brian Meneses-Claudio ${ }^{3}$ \\ Image Processing Research \\ Laboratory (INTI-Lab) \\ Universidad de Ciencias y \\ Humanidades, Lima, Perú
}

\begin{abstract}
In this research, the evolution of change in an organization, due to continuous changes in the market, is disclosed in a qualitative and quantitative way. The changes developed in the organizational structure were aimed at the search for a flexible, dynamic and agile organization, which would allow adapting to the demands of increasingly informed customers, this engine of change called customer required the company to develop a flexible organizational structure. For this, the key concepts were reviewed, such as: systems, processes, activities, modeling and the use of the Systems Dynamics tool for the elaboration of the causal diagram and flow diagram, which allowed to identify, analyze and evaluate the variables that affected each stage of organizational change. The evolution of the change that the organization developed was carried out in an unplanned sequential manner, in the following stages: first a vertical organization, second an organization by processes, third a focused organization, fourth a modular organization and later a flexible organization, which allowed adapt to changes in customer orders, orders that each time increased in the characteristics of the product model, but decreased in quantities. The changes developed by the organization allowed to increase the response speed in order delivery by $43 \%$.
\end{abstract}

Keywords-System dynamics; diagram; vertical organization; process organization; focused organization; modular organization; flexible organization

\section{INTRODUCTION}

The present research work explains the evolution of the organization of an XXX textile-clothing company, in which the level of change in the behavior of its organizational structure was analyzed [1,2], as a result of the level of change in demand in the market. Initially, the company was developed through a vertical structure in a traditional hierarchical and highly bureaucratic way, it was formed by the administrative areas considered as support, and the operational areas that carried out from the storage of raw materials and supplies, transformation to packaging for the obtaining the final product, which are clothing. The company was considered as a system that consisted of a set of productive resources, led by management, decision-making was centralized, as well as the administrative area, the control of this area was done by management, this type of organization [3,4] gave results when the company was in its infancy, but due to the increase in demand for orders, the company began to expand its production capacity by increasing its infrastructure, machines, equipment and personnel for the different operational and administrative areas, it was becoming increasingly clear that the company required new organizational models.

The company exports garments to the US, Canada among other countries, in a greater proportion to the US. These clients requested garments through a contract, their orders were greater than 5,000 garments per model with little variability in color, and type of fabric, it could have one type of application: print or embroidery, or both. The organization was forced to make the change where the type of order was suitable for a mass production line, the higher the production, the utility tends to increase and the unit costs to decrease, and this is due to the variable costs they increase according to the units produced and fixed costs remain constant over time, as can be seen in Fig. 1. Market changes began to appear when customers requested smaller and smaller quantities of garments through their orders to 5,000 garments, with varieties of colors, type of fabric and applications, that is, it became unstable, but this instability brought benefits to the company because it seeks a change from a company with a traditional structure to a dynamic, agile company. Organizations are defined as "open systems whose parts are related to each other and to their environment. The nature of this relationship is one of interdependence because all parts of the system affect and are mutually affected" [5].

In Section II, the methods applied in the collection, analysis and evaluation of information and System Dynamics as a tool for the design of scenario models using the Vensim software. And as an understanding of the development of these models, the concepts of systems, processes and activity are provided. In this section, the evolution of organizational change is rigorously detailed in four stages. In Section III, the results of the organizational change are presented in a quantitative way and graphically presenting its various behaviors from a modular structure to a flexible structure and the incidence of the configuration of production batches in process. In Section IV, the results obtained and the consequences that generated the changes are explained, such as the reduction of personnel, lack of commitment of the personnel and the decisions that the organization makes to reverse the lack of skilled workforce, the prevalence of the organization to maintain control through its authority. In Section V, the conclusions of the obtained results are explained and the future research to be carried out on organizational change through the concepts of chaos and complex systems in a qualitative and quantitative way is presented. 


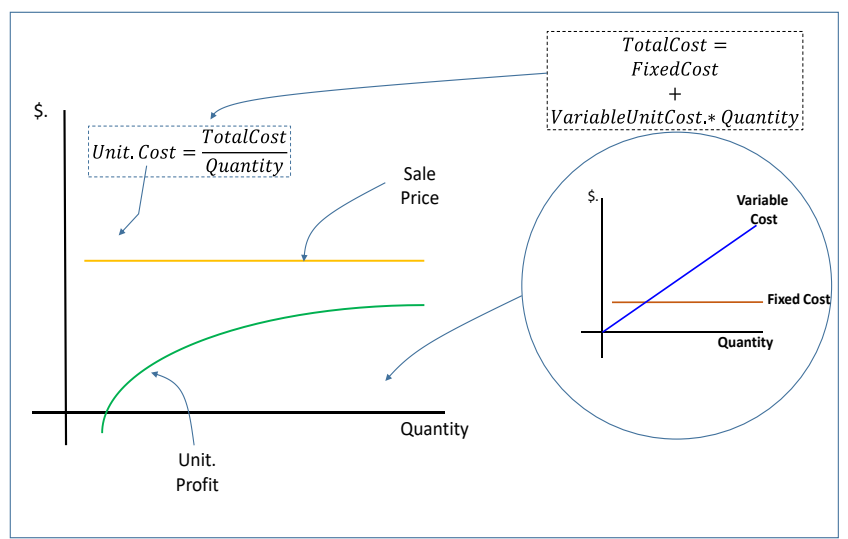

Fig. 1. Fluctuation of Prices, Costs and Profit.

\section{A. Statement of the Problem}

Due to the rigidity with which the organization was developed through a vertical and centralized structure and with operational areas configured as mass production lines, it was not going to meet the changes in customer demand, in such a situation the management needed to respond to the following questions:

- Is the company prepared for a transition and know how to transform this implicit threat into growth?

- If the company with the type of structure could not adapt to changes in demand, what should be the type of agile and flexible organizational structure to demand?

- What positive effects will decentralization of administrative areas generate within operational areas?

- Reconfigure the operational areas from a type of organization by processes to a flexible organization with a pull system, would it adapt to changes in demand?

\section{B. Objective}

It is to make known the stages of dynamic changes and the results of adaptability of the organization, based on the change in customer demand. From a rigid organization to a flexible, dynamic, results-oriented organization, allowing its members to think, innovate, collaborate, improve their capacities and assume a personal commitment to the collective future and to the objectives of the company.

\section{Hypothesis}

A flexible organization is a dynamic and agile organization that adapts to changes in market demand, with personnel specialized in carrying out different types of activities that add value, in handling different types of machine, in the shortest possible time, reducing lead time, the costs of its resources and producing only the quantity requested by the client, efficiently and effectively fulfilling delivery times and with superior quality for the client.

\section{Methodology}

The method used in the present study is empiricalanalytical because through the stages of implementation of the change in the organizational structure, direct experience was acquired and the evidence of the assimilation of the change was collected in each stage, making itself known in the present research work.

Also, a quantitative method because through the change that was made, the Systems Dynamics tool was used for modeling scenarios, identifying the relationship and interaction of the variables involved, assigning numerical values and algorithms, to apply formal techniques to the study.

\section{A. Systems Dynamics}

Systems Dynamics is a tool that allows to analyze the level of behavior of a certain system, the interaction, the cause and effect of the variables that intervene $[6,7,8]$, it also allows simulations through the construction of scenario models which we will do through of the Vensim software, defining the types of variables that act and interact. Through it, the level of incidence between the areas was evaluated: administrative with the operational part through the development of causal diagrams and flow diagrams.

Causal diagrams analyze the cause and effect that occur between two variables:

- $\uparrow \mathrm{A} \rightarrow \uparrow \mathrm{B}$, if variable $\mathrm{A}$ increases or decreases variable $\mathrm{B}$ will also present the same behavior.

- $\uparrow \mathrm{A} \rightarrow \downarrow \mathrm{B}$, if variable $\mathrm{A}$ increases or decreases variable $\mathrm{B}$ will present the opposite behavior.

This tool allowed to carry out experiments, gathering knowledge of the system, initially in a non-structured way, but as the cause-effect relationships of the variables were understood, this knowledge was organized in a more structured way [9].

\section{B. System}

A system is a unit that is formed by a set of elements that interact with each other, to achieve a common goal [10, 11, 12]. The company as a system is visualized through an organization chart, where the set of areas that is organized is observed. Each area has a function and resources for the fulfillment of its objectives, as well as the level of responsibility. It can also consider that each area is a subsystem and is also made up of resources that interact towards a specific objective.

\section{Process}

A process $(\mathrm{P})$ is formed by a set of sub-processes $(\mathrm{Sp})$ and each sub-process by a set of activities (a), it can also be considered that a process is made up of a set of activities, this will depend on the type of development of the organization $[13,14,15]$.

$P=\sum_{j=1}^{n} S p_{j}, S p=\sum_{i=1}^{n} a_{i}, P=\sum_{i=1}^{n} a_{i}$

In operational processes, there are two types of push and pull systems. The push system adjusts to the capacity of the activity carried out by pushing the raw material, products in process or finished products from one activity to another, in this type of system inventories are presented, this is due to the difference in capabilities between activities. 
The pull system [16] adjusts to market demand, when demand is present, production becomes effective. In this type of system, it does not present inventories since production is carried out according to the order between activities, that is, the activity that precedes pulls the raw material or product in process to the activity that precedes it. As will be seen later in the development, the change and their implementation of these systems in the operational areas had an impact on their adaptability to customer demand.

\section{Activity}

An activity (a) is made up of a set of tasks [17, 18], executed by the person or machine and person-machine. For each process, the following resources used were identified:

$$
\begin{aligned}
& \text { Cut } \rightarrow \text { a }=f(T, \text { RM, Inp, Mac., Pers., T.) } \\
& \text { Sewing } \rightarrow \text { a=f (Mac., Pp, Pers., T.) } \\
& \text { Cleanliness } \rightarrow \text { a=f (T, Pp., Pers., T.) } \\
& \text { Review } \rightarrow \text { a=f (Pp, Pers., T.) } \\
& \text { Packing } \rightarrow \text { a=f (Mac., T, Inp, Pp, Pers., T.) }
\end{aligned}
$$

Where:

$\mathrm{T}=$ Table, $\mathrm{RM}=$ Raw Material, Inp. = Input, Mac = Machine, Pers. $=$ Personnel, $\mathrm{Pp}=$ Product in process, T. $=$ Tool.

\section{E. Model}

A model is an object that represents another object. As defined by Marvin Minsky [19], "For an observer O an object $\mathrm{M}$ is a model of an object $\mathrm{S}$ and an experiment $\mathrm{E}$, if $\mathrm{O}$ can use $\mathrm{M}$ to apply $\mathrm{E}$ and solve important questions in relation to $\mathrm{S}$ ”.

\section{F. Dynamics of Organizational Change}

The management began to develop changes in the administrative areas and in the operational areas, the objective is for the company to be flexible to changes in demand. The administrative and operational organization must be able to adapt to rapid changes in demand efficiently and effectively. The type of organization that was developed was a vertical and rigid structure, the level of information from the operational and administrative areas reached the management for control, evaluation and decision-making, time was very limited for the review of all the reports. Faced with such complexity, management chose to make changes in the administrative areas as well as in the operational areas. Although, the changes developed by management were not planned but guided by instinct.

The change process in a given organization goes from top to bottom, management leadership for change determines the level of strength, flexibility and agility of the organization's response to the client. As the following researchers point out:

Gonzales [20] "in order to have adaptable organizations, it is necessary to create heterarchical structures, with flexible and flat models".
Ponce [21] "the company's ability to integrate, build and reconfigure internal and external competencies to address rapid changes in the environment."

The fundamental thing about change in an organization is that it remains constant, for this the design of the organization must be supported by a decentralized and flexible hierarchical structure: encourage teamwork, exchange and delegation of power: and put in motion systems that recognize and celebrate personal achievements.

The unplanned changes began in the operational part and later in the administrative part, as follows:

1) 1st Change from a vertical structure to a process structure: In this type of vertical organization, the administrative part was separated from the operative part, as shown in Fig. 2. In the administrative part are the areas of Planning, Purchasing, Quality, Accounting, Modeling, Systems, Maintenance and Commercial. The Maintenance and Quality areas were centralized within the administrative part, not as part of the transformation of the product but as support areas for the operational part. The objective of the management was to maintain control of the administrative part, and the decisions of the management of the operative part were entrusted to the production manager, which only reported to the management the progress for each production order. The characteristic in this type of organization was that the communication flows are vertical from top to bottom and spread through the hierarchical structure, the leadership of the organization was in charge of an insider that is, the management controlled every activity that was executed in the administrative part. This organization provided a stable and predictable environment, it was conceived as a machine, the objective of the administrative and operational staff was its self-preservation, and physically the administrative part was separated from the production part.

As this type of structure did not help the strategic objectives of the company, changes in the organizational structure began, especially in those operational processes that used more labor, machine and production time and it's began from the receipt of the raw material, transformation, to turn into a final product such as the warehouse, cutting, sewing, cleaning-review and packaging areas.

In this type of organization, as can be seen in Fig. 3, the company developed it with the aim of maintaining control of the capacity and ability of each operating process separately, when it enters a certain garment model for its manufacture.

The type of demand requested by the client through a contract, the company converted it into a production order for internal administrative management in all operational processes, and the production orders were higher than 5,000 garments, the degree of complexity in their Manufacturing was minimal since it presented a single type of fabric, fewer than four colors, each color on average was 1,250 garments. 


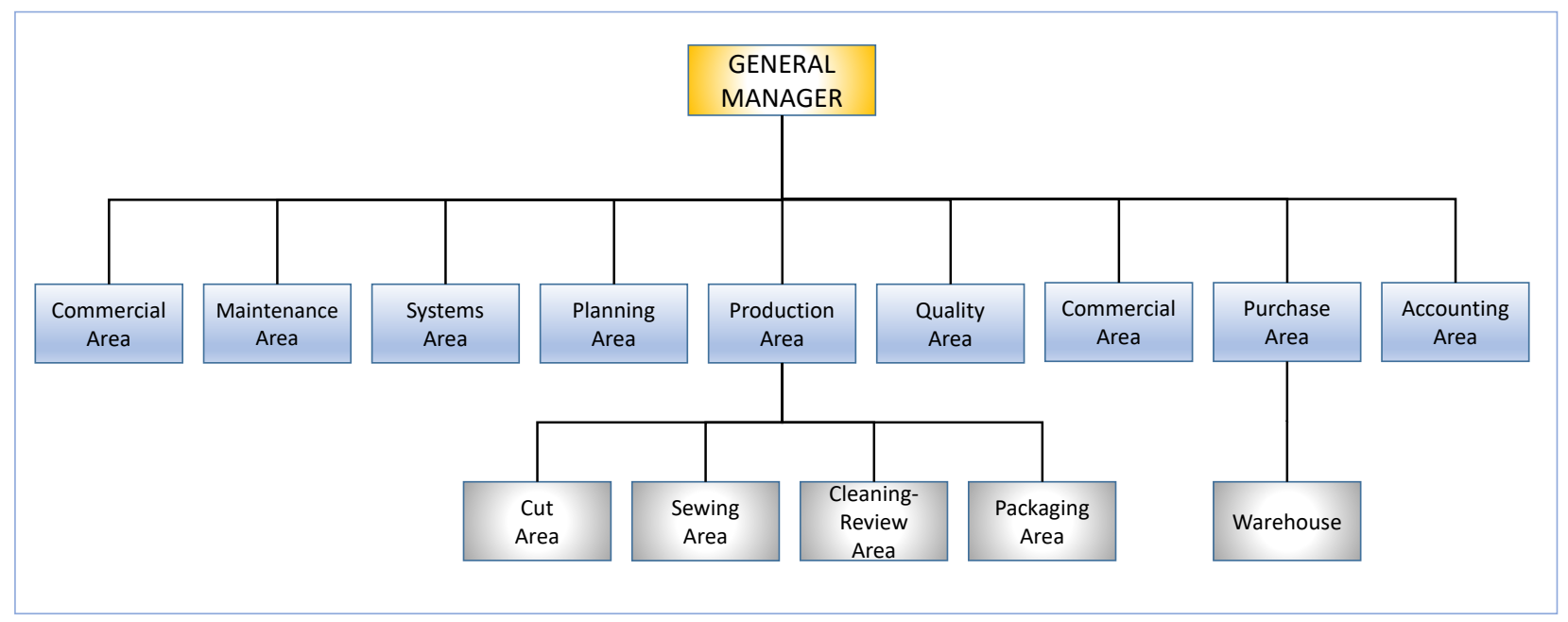

Fig. 2. Vertical Organization Chart.

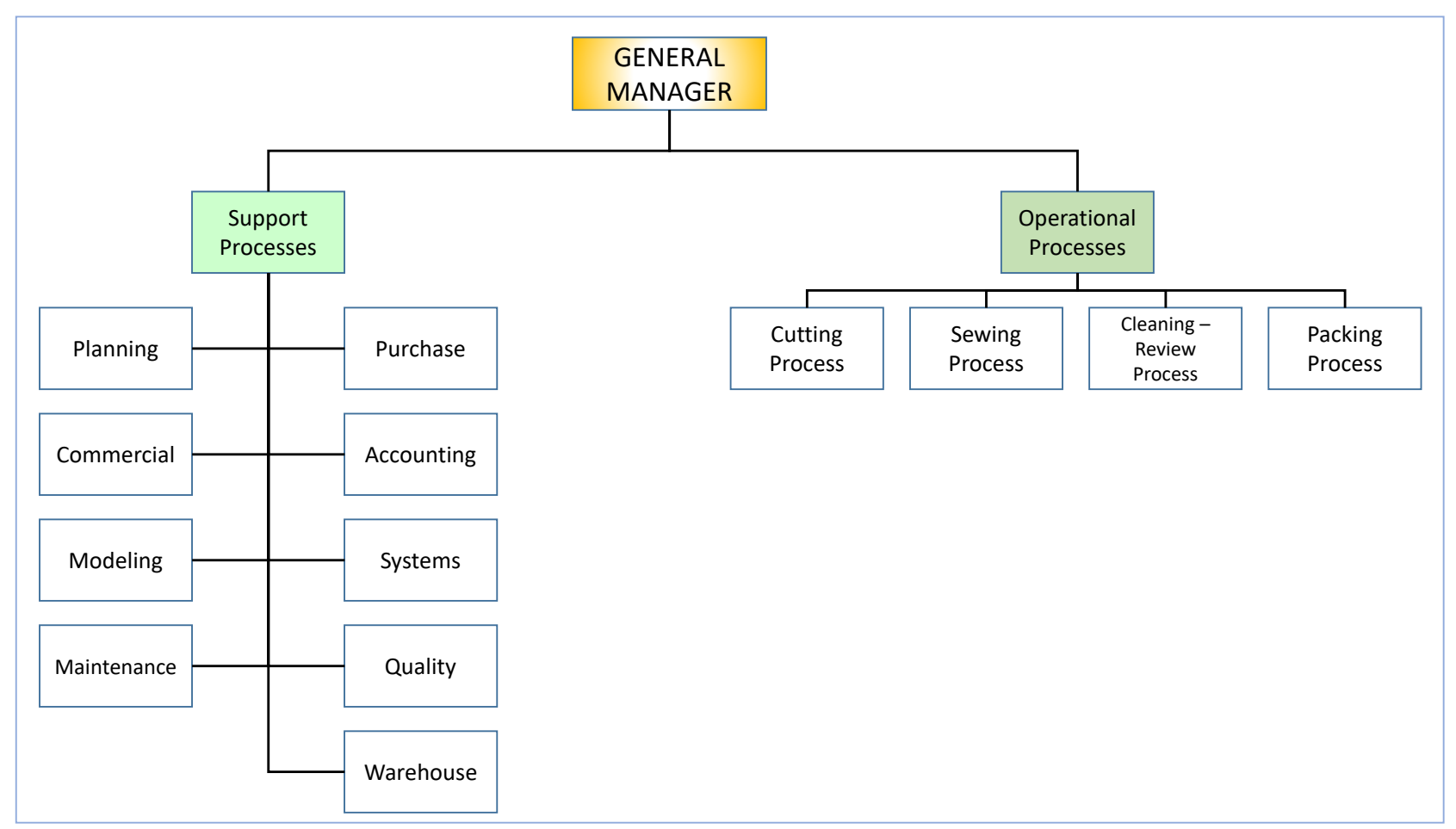

Fig. 3. Organization Chart by Processes.

The cutting area received the information of the production orders, coming from the planning area and the fabric from the dyeing area, later it made the cut according to the FIFO method (first in, first out), that is, the first to arrive is the first cut and then sent to the sewing area or according to the programmed date of entry to sewing. It was commonly carried out according to the FIFO method, since removing the laying of the fabric that was on the table was unproductive for the cutting area, the area manager avoided that in the monthly report that he presented to management, efficiency and productivity were low.

This decision of the cutting area affected the availability of time in the areas that preceded it, such as: sewing, cleaningreview and packaging. Progressively, the time available was reduced for its delivery, that is, the cutting area did not consider the needs of its internal client.

In order that these areas are not affected by noncompliance on the delivery date to the customer, the sewing, cleaning-review and packaging supervisors increased with productive hours, carrying out the overtime programming, especially the packaging area which was the area with the least available hours at the end of the entire process, this type of decision affected manufacturing costs.

The clothing area, maintained a planned production according to its capacity applying the push system as can be seen in the Fig. 12, it was configured as a mass production line, that is, the sewing operations that preceded the previous operation should wait, until the assembly of the garments of 
the batch production was completed, not presenting a continuous production flow but unproductive times between activities, although its flow presented a consecutive sequence according to the sewing activities of the garment model. Its speed and its skill level of the seamstresses at the beginning of production of the model was low, but as time passed, it increased its production of the same model, the staff increased their degree of skill and speed since the activity was monotonous, performing the same operation on the same machine and its level of defects was minimal. The operational ability of the sewing personnel only had dexterity in the handling of a single type of machine, performing different types of complex and non-complex operations, their salary was piecework, that is, according to what they produced, they did not assume the challenges in handling other types of machines, in addition to the fact that the applied production system did not allow it. For the present cause and effect model, the relationships of each of the variables are exposed as shown in Fig. 4.

Client: This variable, made up of other variables, has a positive influence relationship with the orders it places, and presents a positive feedback with the receipt of the shipments made by the company.

Production: The quantity produced is positively influenced by the number of orders placed by the client, and is also negatively influenced by the number of work centers, production time, and the number of defects.

Ability: It is a variable that is related to the activity carried out by the person, and has negative influences: with the number of personnel required, with the production time and the defects due to the execution of their activity.

Dispatch: It is a compound variable that is positively influenced by the quantity produced and that has a positive influence on clients.

Continuously in the sewing process, the supervisor controlled the Lead Time or processing time as seen in Fig. 5, when a garment model change occurred, before entering the production unit or batch to the line, the supervisor carried out the distribution of personnel and machine, executed in any of the following ways:

a) When personnel were placed in the machines in a single time. Here, waiting or unproductive times were presented from the second operation and accumulated until the last sewing operation. The waiting time between activities is directly related to the size of the production batch, as observed in equation 1 and 2.

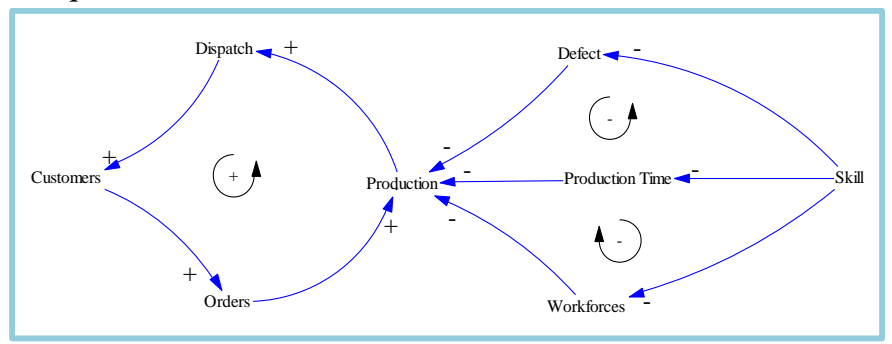

Fig. 4. Cause and Effect Diagram.

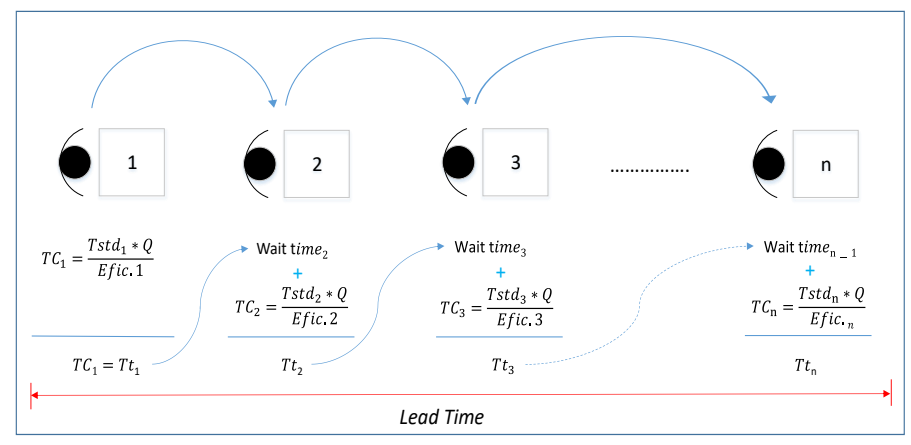

Fig. 5. Lead time with Waiting Times.

LeadTime $=$ WaitingTimes $+\frac{\operatorname{Tstd}_{n} * Q}{\text { Efic.n }}$

Waiting Times $_{n}=\frac{\text { Tst }_{n-1} * Q}{\text { Efic.n-1 }}$

$\mathrm{TC} n=$ Sewing time of activity " $\mathrm{n}$ ".

Tstdn $=$ Standard time of activity " $n$ "

$\mathrm{Ttn}=$ Total time in sewing activity " $\mathrm{n}$ "

$\mathrm{Q}=$ Number of pieces per package

b) When personnel are located as the batch of 20 units progresses for each operation, the waiting time does not appear, for this the supervisor must previously schedule activities for the personnel before being placed on the line, as observed in Fig. 6 and equation 1.

In Fig. 7, the causal diagram is shown where the causeeffect relationship between the administrative part and the operational part is revealed, the greater the physical separation distance between these areas, the less their interaction and communication. The administrative part presented ignorance of the programmed orders in the processes, control and ignorance of the operational decisions. The reports presented by the administrative areas to the operative part were inadequate, since in the operative part it generated limitations in the management of their productive resources which implied problems of quality, productivity, efficiency and effectiveness, due to lack of coordination and adequate information and timely, which presented organizational confusion and delays in the delivery of production orders to the client in the requested time.

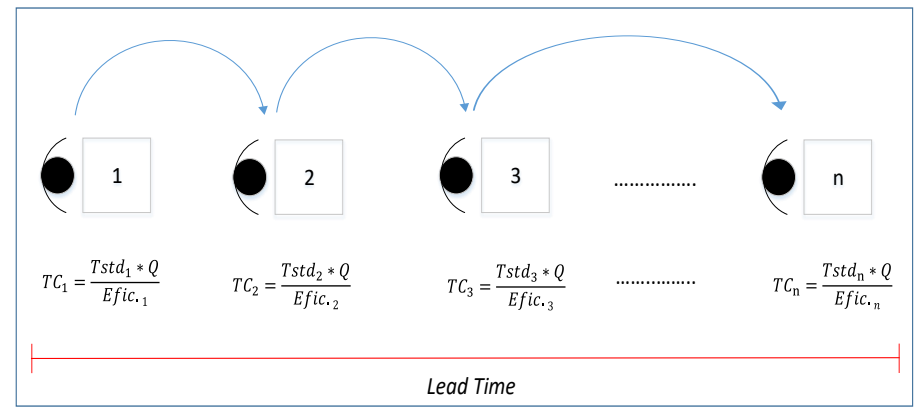

Fig. 6. Lead Time without Waiting Times. 


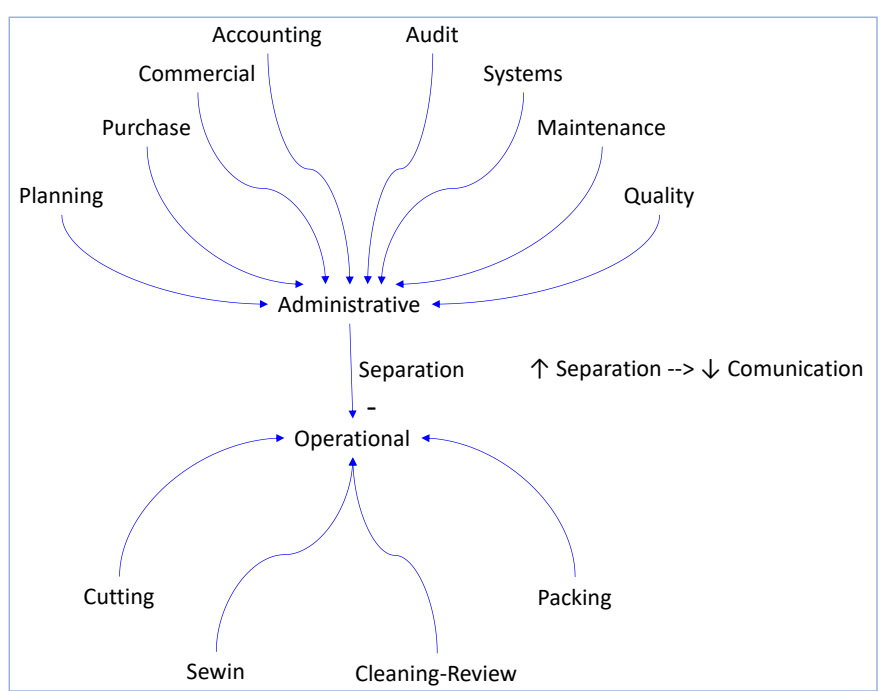

Fig. 7. Causal Diagram: Greater Administrative-Operational Separation.

Each operational area was physically separated and was responsible for its own process and sought in any case to increase its productivity, quality and efficiency, but it did not observe its internal client, that is, the other processes that carried out the transformation of the raw material or product in process. The cutting area carried out its activities in the shortest possible time and sent the fabrics cut into pieces by transport to the sewing area for their preparation, in this area as it was observed that some pieces cut within the packages did not comply with the measurements according to the specification sheet, which was returned to the cutting area for rectification or replacement, in the same way it was presented in the cleaning-review and packaging process, the accumulation of unproductive times due to return each time it increased for each operating area, presenting a bottleneck, limiting its advance for each production order.

2) 2nd change from a process structure to a focused organizational structure: In this type of organization, although the operational processes were still physically separated, as shown in Fig. 8, internal changes were made in each process. The cutting process that consisted of a set of tables was organized so that each of them worked taking into account the garment model, in the same way it was carried out in the sewing, cleaning-review and packaging processes, with the aim of maintaining a linear orientation at the flow level, which allowed better coordination between processes and better control for those in charge.

In this type of organization, it was considered more orderly since it was identified which are the sub-processes and activities for each process as shown in Fig. 9, which allowed better control of production and quality control. In the cutting process, a single type of model was assigned for a certain table, its degree of complexity decreases and its efficiency increases, its production time is less and less, as well as the machine configuration time (set up), which allowed to reduce operating costs, in the same way it was organized for the sewing, cleaning-review and packaging processes. But the administrative part was still detached from the operational part and under management control, which continued to affect the level of communication.

3) 3rd change from a focused structure to a modular structure: As can be seen in Fig. 10, the change developed in the operational part is the implementation of modules, which is constituted by a set of processes and organized sequentially according to the construction of the garment model and that combine different types of machines and multi-functional people to execute different types of activities within each subprocess or process, with the objective of transforming a complete production unit. Within its characteristic, it can be noted that there is a high level of operational communication, the production flow is aligned and continuous. It presents higher quality in the activities, increases the production speed, that is, reducing manufacturing times and reducing operating costs.

This type of organization implemented by the company, each module consisted of the areas of cutting, sewing, reviewcleaning and packaging, as seen in the organization chart, and was carried out as a result of the client's demand increasing in orders, no longer in quantity per model but in variety, from a production order of 5,000 garments it was now the equivalent of 10 order orders with different types of models, different types of fabric, different colors and with stamping or embroidery applications, with minimum quantities for each color.

With the type of focused structure on which the sewing process was configured as a mass production line for orders greater than 5,000 garments, it could not be adapted to orders of less than 400 garments, what was to redesign the production lines for minimum quantities.

With this type of organizational change, the company only focused on operational processes, which consumed more activity, personnel, machine and production time, such as: cutting, sewing, cleaning-review and packaging. The area was redesigned in a modular way, so that these activities are within them led by a boss. The distribution of the process, subprocesses and activities within the module, must have a sequential form maintaining a constant flow of production, with the same configuration of the batch or production unit from the beginning of the cutting activity, passing through all the activities of sewing, cleaning-inspection and packaging as seen in Fig. 11.

The distribution of the production batch between activities continued to be maintained with the push system, as shown in Fig. 12. In this type of modular organization, a higher level of interaction between processes, sub-processes and activities was observed since it was within one module, it was more dynamic, the control and exchange of information was more fluid and effective, and the degree of response and communication was greater. But the interaction with the administrative areas was still inefficient, since it was physically separated from the operative part and inadequate or delayed information continued to be presented for the operative part. 


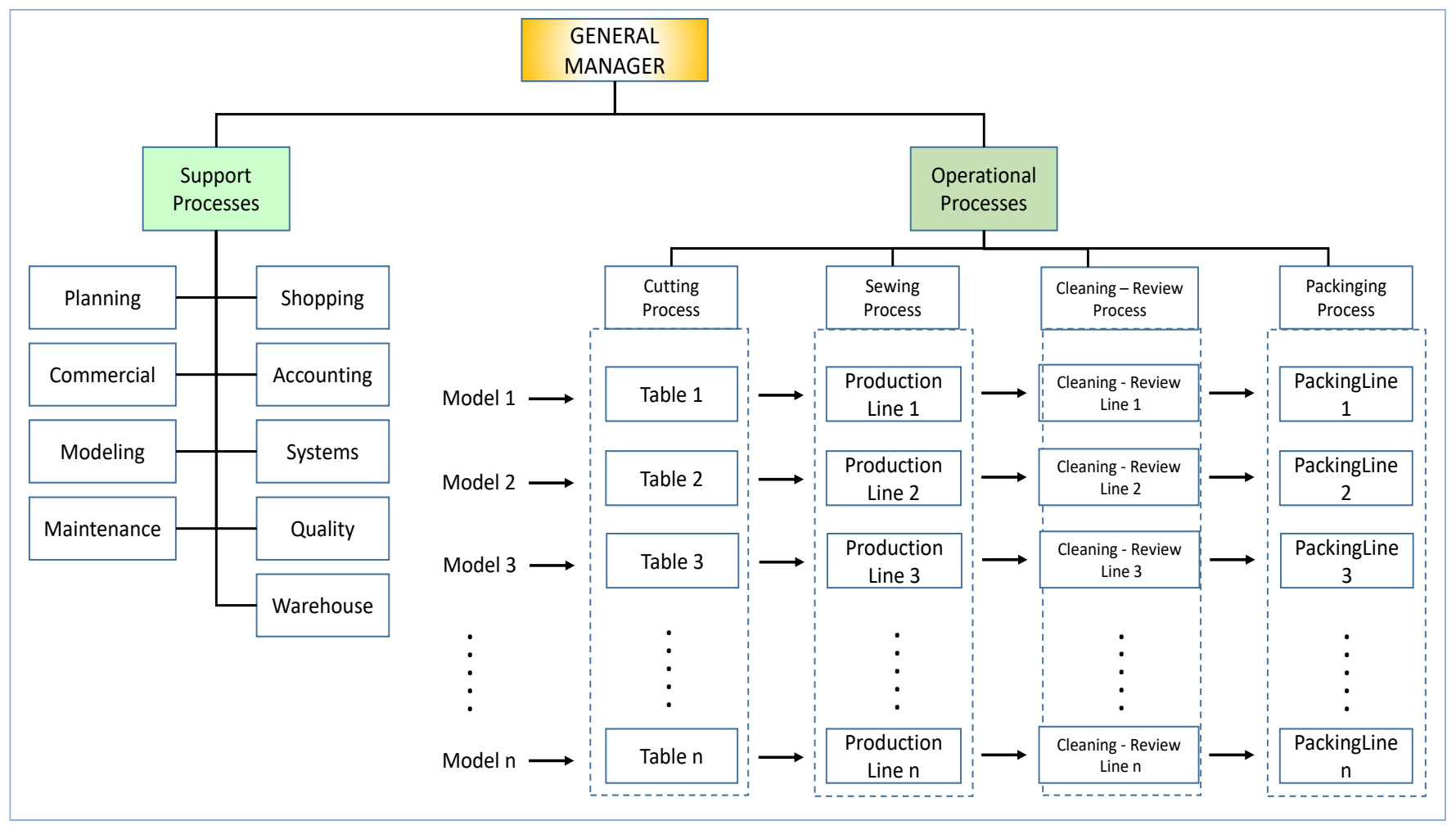

Fig. 8. Model Focused Organization Chart.

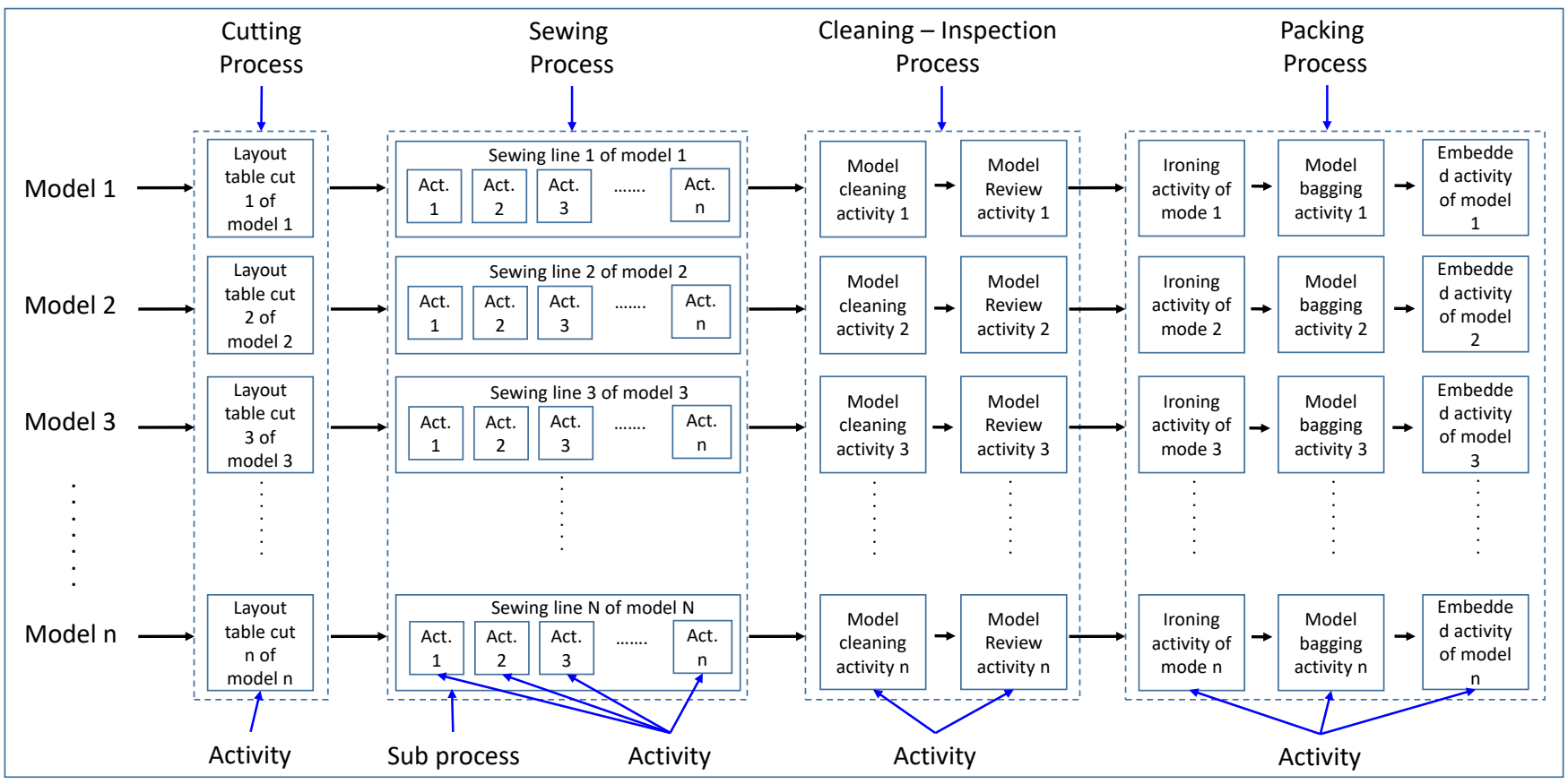

Fig. 9. Organization by Processes, Sub-processes and Activities. 


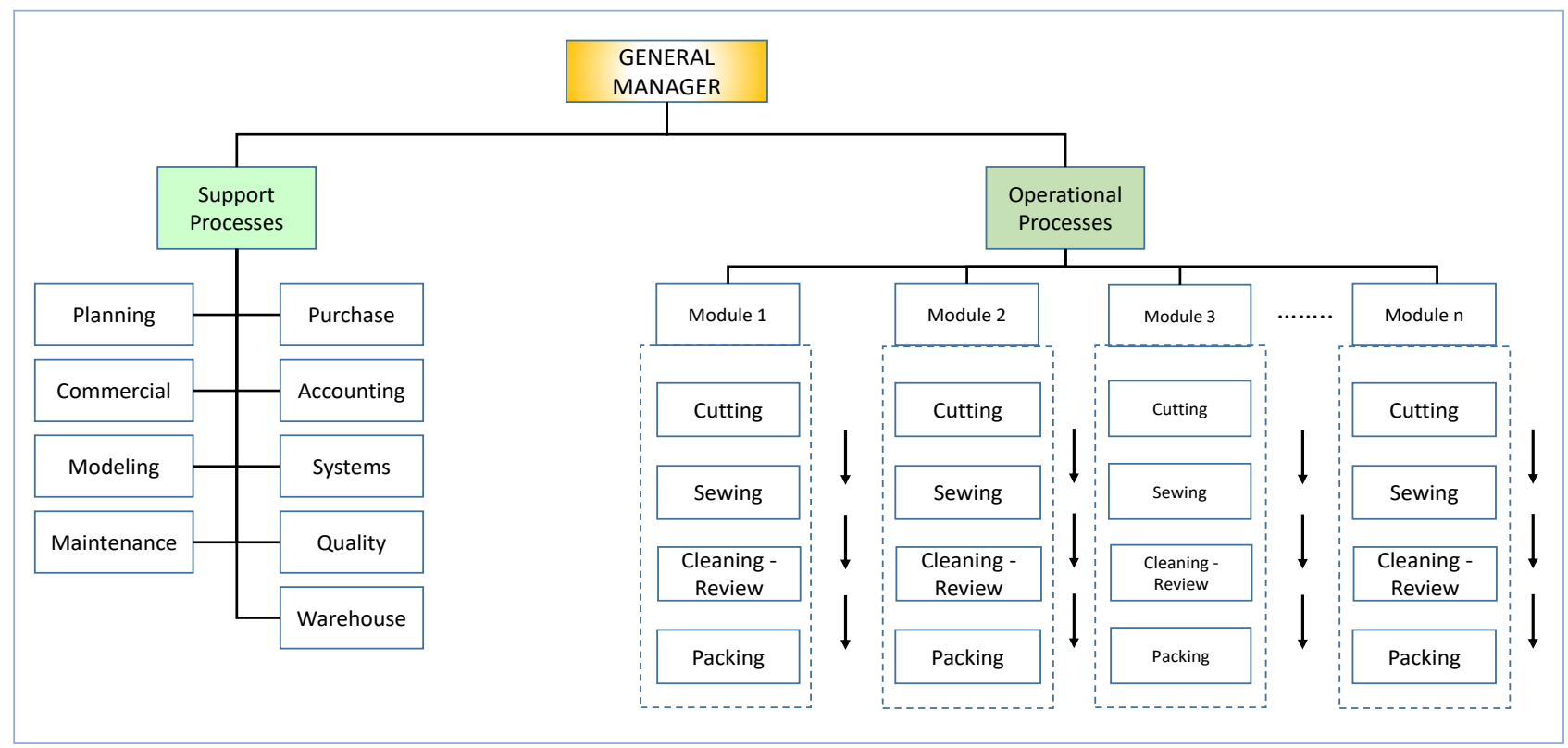

Fig. 10. Modular Organization Chart.

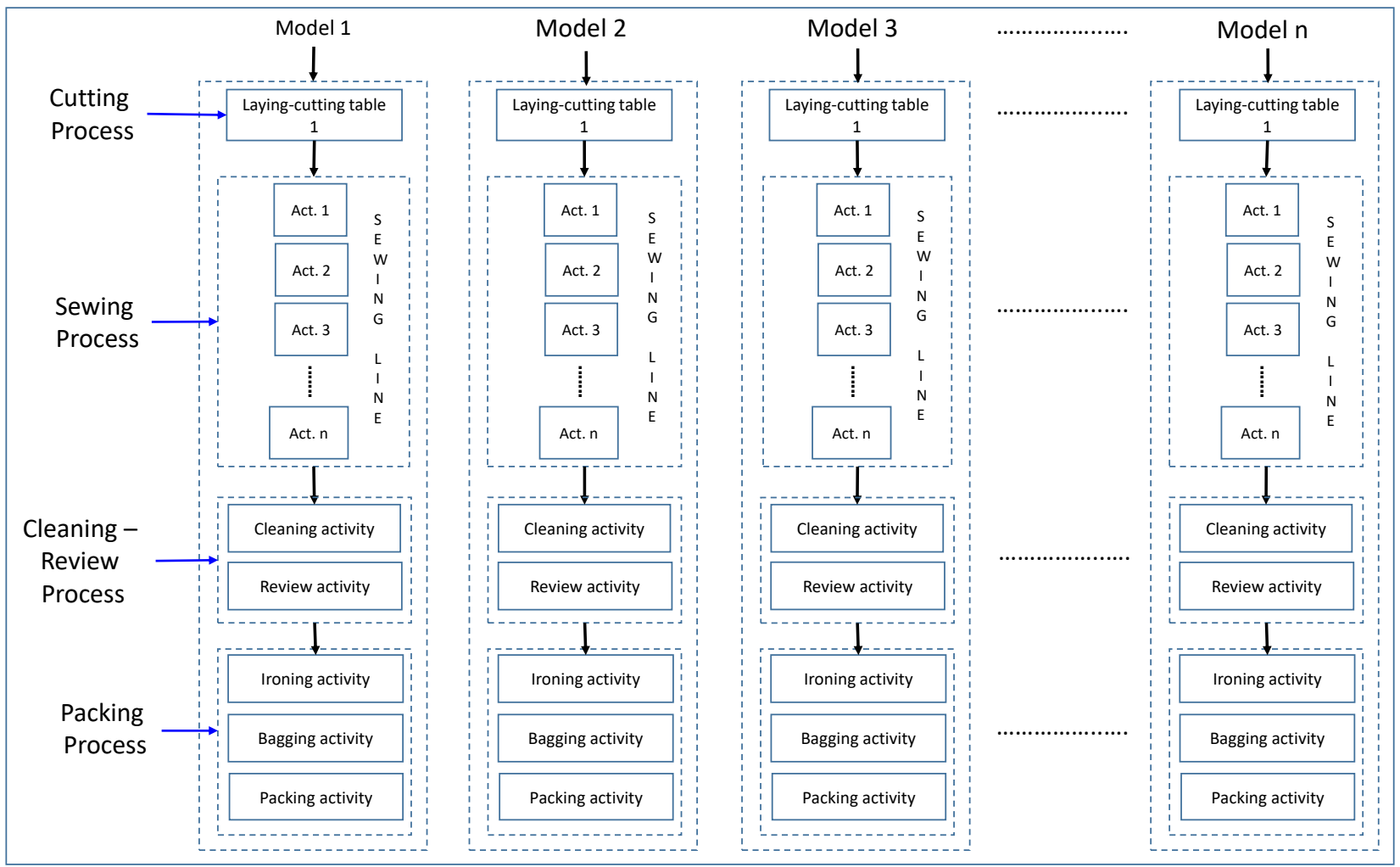

Fig. 11. Organizacion por Modulo de los Procesos Subprocesos y Actividades.

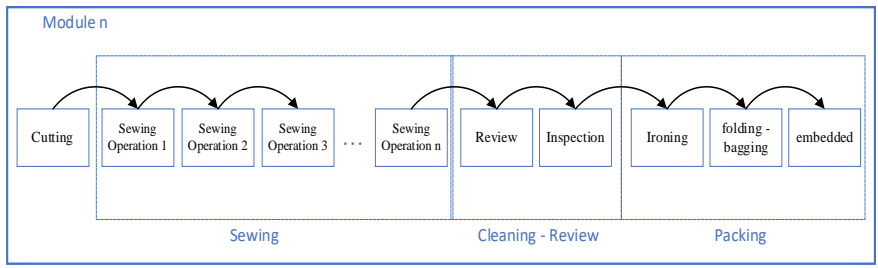

Fig. 12. Push System. 
a) Flowchart: The development of this diagram was carried out to understand the variables that influence the production system, in order to quantitatively determine the level of incidence of the variables and how changes affect the system, as a previous step to the simulation. It should be remembered that, in the hypothesis to be solved, is that the organization identifies and executes activities that add value, through the variables requested, days required, efficiency, defect levels and lead time, which affect each process, it can identify quantitatively the limiting effect on the system. Fig. 13 shows the flow diagram that is made up of 23 constants, 15 auxiliary variables, 10 flow variables and 5 level variables.

\section{b) Dynamic Formulation of a Modular Structure}

TTU: Total Time Used by the area (cutting, sewing, cleaning, Review and finishing).

$T T U \_a r e a=T C \_a r e a+T P \_a r e a+T T \_a r e a$

TC_area $=$ Loading time of the area (cutting, sewing, cleaning, Review and finishing).

$T C_{\text {area }}=\frac{Q_{\text {area } * T s t d_{\text {area }} * \# \text { package }}}{\text { Efc.area }}$

Where:

Q_area $=$ Number of units per package or batch.

Tstd_area $=$ Standard time of the model that is carried out in the area.

\#package $=$ It is the first package or batch that enters the area. perform the configuration of machines and the degree of skill of the personnel to carry out the assigned operation are considered.

TP_area: Production time of the area (cutting, sewing, cleaning, Review and finishing).

$T P_{\text {area }}=\frac{\text { Ped. } * T s t d_{\text {area }}}{O p_{\text {area }} * E \text { fparea }_{\text {are }}}$

Where;

Ped. $=$ The quantity ordered by the client.

Tstd_area $=$ Standard time of the model that is carried out in the area.

Op._area $=$ Number of operators assigned to the area for a specific model.

Efp_area= Production efficiency of the area regarding to the model.

TT_area $=$ Time for transfer of production to the next area.

$T T_{\text {area }}=\frac{T P_{\text {area }} * T t_{\text {area }}}{\text { T.dispon }}$

Where:

TP_area $=$ Production time of the area (cutting, sewing, cleaning, Review and finishing).

TT_area $=$ Transportation time performed by the preceding area.

T. dispon= Time available for the area.

Efc_area $=$ Load efficiency of the first package of the model that enters the area. The speed in the use of resources to

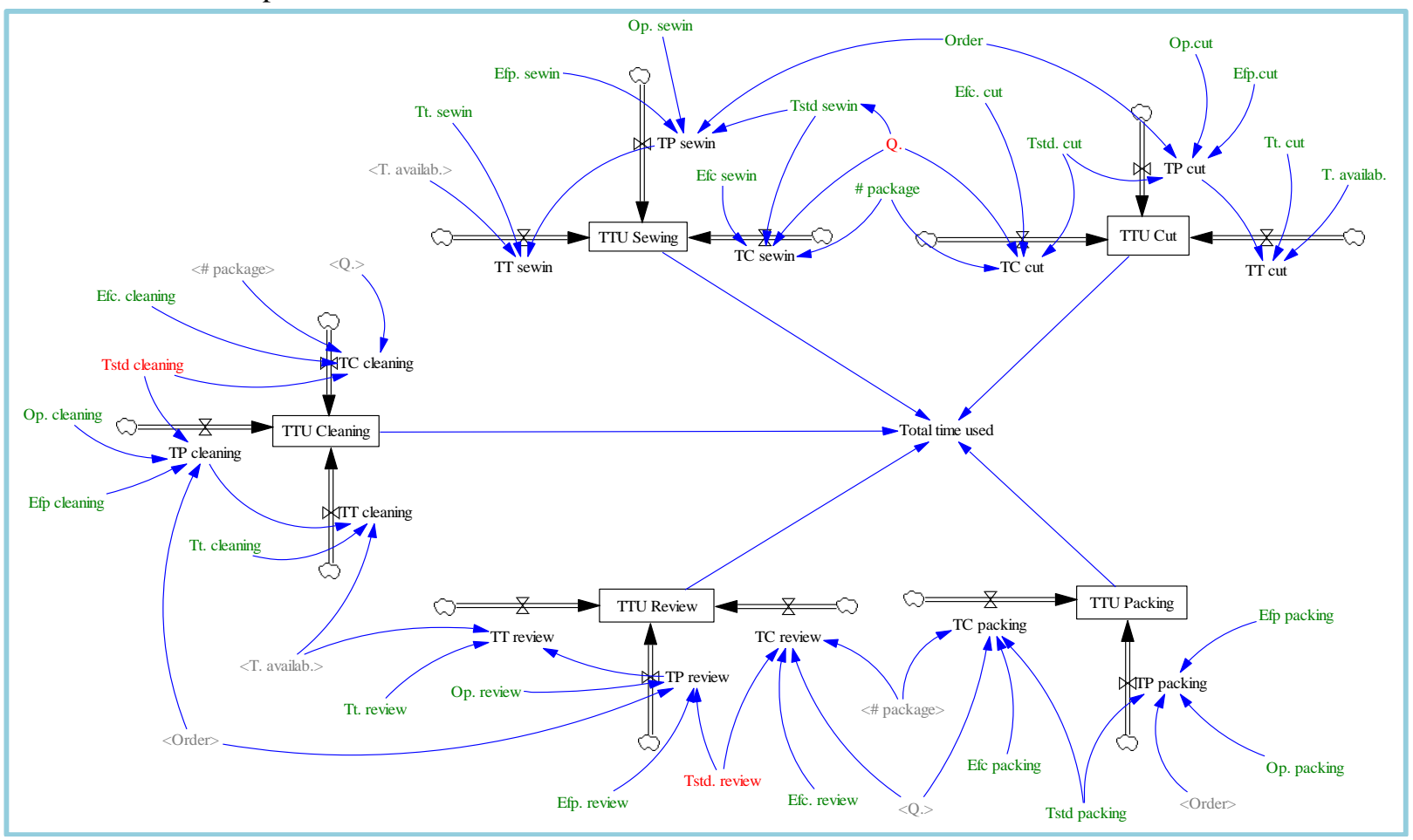

Fig. 13. Manufacturing Flow Diagram. 
4) 4th change from a modular structure to a flexible manufacturing: As the administrative areas were not effective in communicating and transferring information with the operational part due to the physical separation distance, the management made the decision to distribute the personnel in charge of planning, purchasing, commercial, maintenance, quality and payroll, (Regarding to the last one, this function was considered in replacement of accounting), within each module, as observed in the causal diagram of Fig. 14, the smaller the separation distance between the administrative and operational areas, the greater the level of communication and under the direction of the head of module.

The responsibility of the dispatches of the production orders fell to the head of the module, as can be seen in the new organization chart in Fig. 15. This type of decentralized organization [22] presented autonomy in the module to make its own decisions, which generated effects positive, there was already more interaction between the administrative and operational part within the module, as Vásquez points out [23] "Reinforcing communication processes and strengthening social and human capital through teamwork and communications".

In addition, changes were made in the operational part, the cleaning and Review processes as it did not generate added value to the product only inventories, waiting times, occupation of spaces and consumption of resources, their permanence generated a negative effect, since when the operating personnel of the sewing department observed this activity carried out by manual personnel, it did not give the importance of quality in its activity, generating even more reinspections and reprocesses, which shortened the delivery time to the client, in addition to considering that the sewing lines were configured as a mass production with push system, the personnel at least knew how to operate one type of sewing machine. For this, the management made the decision to implement a training area, with the aim of training personnel in the handling of three types of machines (serger, coating machine and straight) at least, to perform different types of complex and non-complex activities, in other words, those activities that take longer, in addition, the same sewing staff must clean the garment, trimming the threads by using a picket and reviewing its activity avoiding the occurrence: skipped stitch, thread tension, thread breakage, etc., before to move on to the next activity.

Given the increase in time for carrying out these activities, the payment method was modified, from piecework (individual) to group, according to the amount of garments made by the sewing line. The type of training developed by the company to the operational personnel, facilitated the module supervisor in making decisions to assign activities in the event of any absence, since the personnel had the training and ability to handle any type of machine, which allowed avoid bottlenecks or extend overtime for any need with the available staff. It was also considered to modify the production system from the push system to the pull system [24], such as in Fig. 16. For the implementation of the system, the batch or production unit of 20 garments was modified to one garment, that is, the Inventory in process and the sewing activities that preceded should pull the progress of the previous activity, the objective of reducing downtime between activities and meeting the delivery to the customer in the requested time.

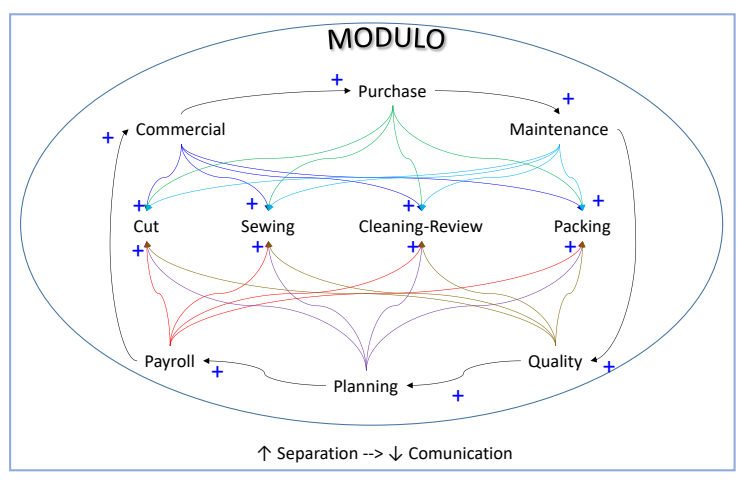

Fig. 14. Causal Diagram: Minor Administrative-Operational Separation.

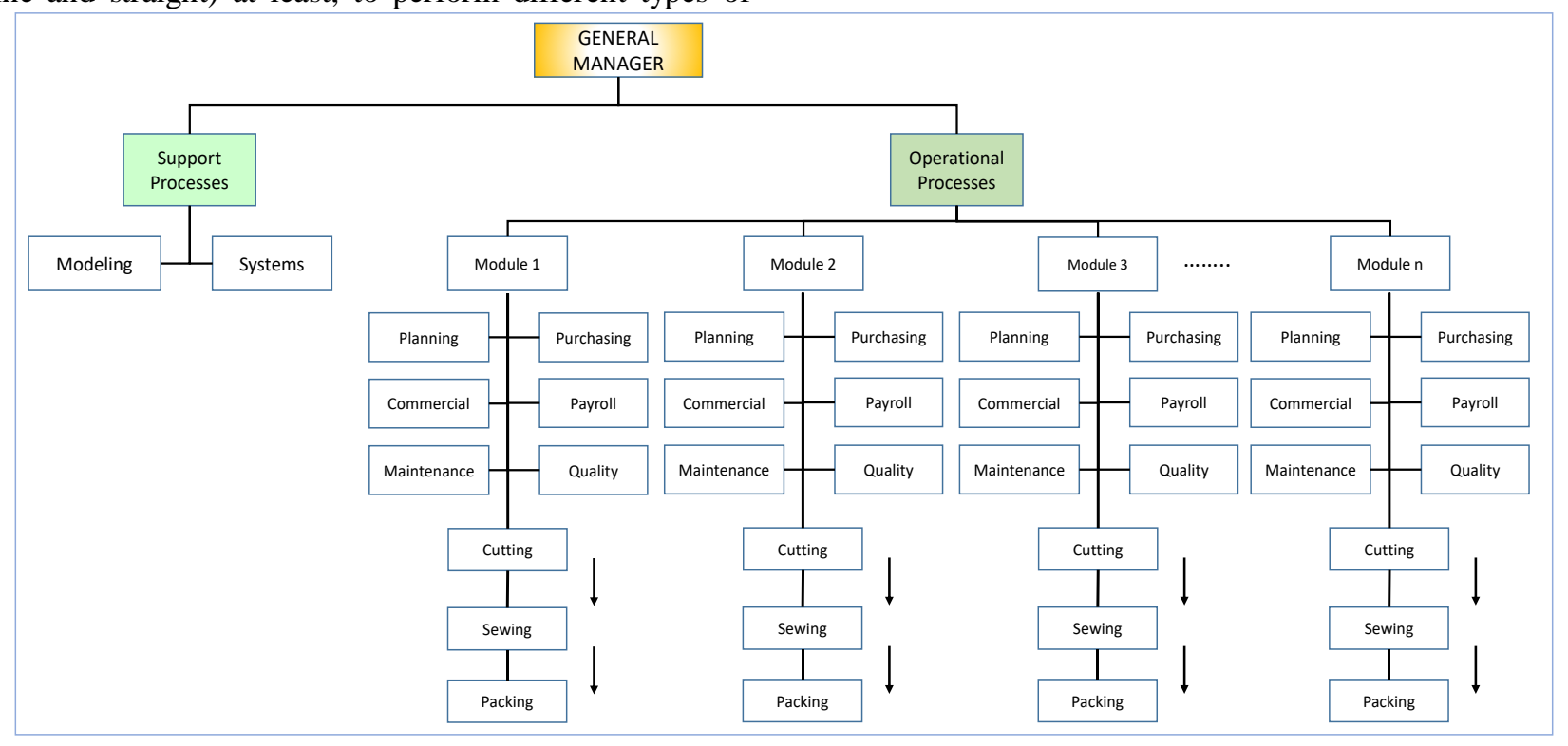

Fig. 15. Flexible Organization Chart. 


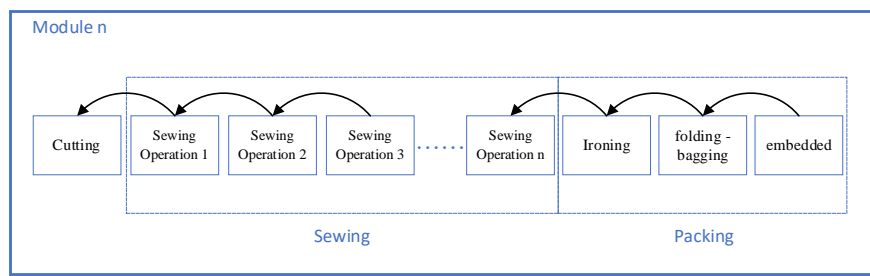

Fig. 16. Pull System.

Considering the changes made in the modules and the available times, standard times and assigned personnel, each person in charge of the area began to carry out their planning, programming and control of their production processes according to their new flexible structure, determining the required loading times, production time and delivery time to the client.

\section{RESULTS}

The management maintained a high level of leadership that allowed the organization to seek to adapt to changes in the external environment, its leadership project perseverance, creativity and innovation to change. To compare the results obtained by the application of a Modular structure with a flexible structure, the following Table presents 1, 2, 3, 4 and 5 the parameters or constants used in the flow diagram in Fig. 13.

Tables I, II, III, IV and V detail the entry of the initial information for each area: the order, available time, loading time of the batch in the process, the production batch or package as a work unit within of the processes, quantity that is constituted in a batch, efficiency of the area, standard production time of the garment model, number of operators used by each area, average efficiency of the personnel and their total time.

Comparing these results with the application of a flexible structure, where the cleaning and review areas are no longer considered within the operational organization and the application of the pull system, configuring as a production batch of one unit, the following variables were modified of the same scenario flow, entering the following data:

$\mathrm{Q}=1$ garment / (package * operators).

Tstd Cleaning $=0$ minutes $*$ operators $/$ garment.

Tstd. Review $=0$ minutes $*$ operators $/$ garment.

As can be seen in Fig. 17, the behavior of the loading time in the production line of a batch of 20 garments is greater than the loading time of a unit. The reduction times were:

- Cut load time reduced from 13.11 to 0.655 minutes.

- Sewing load time reduced from 133.52 to 8,664 minutes.

- The loading times of the cleaning and review areas were reduced to zero, since these were eliminated from the process since they did not add value to the product.

- Finishing area loading time reduced from 27.55 to 1.3755 minutes.
As the cleaning and review areas are no longer presented in the flexible structure, the personnel were reduced by $19 \%$. As a result of the changes made, the organization presented a faster response speed reducing its loading time by $43 \%$, in Fig. 18, it is observed quantitatively without considering and considering the changes made by the organization.

TABLE I. PARAMETERS OR CONSTANTS USED FOR THE CUTTING AREA, AS INPUT IN THE FLOW DIAGRAM OF FIG. 13

\begin{tabular}{|c|l|l|c|}
\hline \multicolumn{2}{|c|}{} & \multicolumn{1}{|c|}{ Unity } & Modular Structure \\
\hline \multicolumn{2}{|c|}{ Order } & Garment/Order & 5,000 \\
\hline \multicolumn{2}{|c|}{ T. dispon. } & Minutes/Day & 480 \\
\hline \multirow{4}{*}{ TC Corte } & \# package & Package/Order & 1 \\
\cline { 2 - 4 } & Q. & garment/ (package * operators) & 20 \\
\cline { 2 - 4 } & Efc. Cut & Dmnl & $90 \%$ \\
\cline { 2 - 4 } & Tstd. Cut & minutes * operators / garment & 0.59 \\
\hline \multirow{3}{*}{ TP Cut } & Op. Cut & Operators & 3 \\
\cline { 2 - 4 } & Efp. Cut & Dmnl & $80 \%$ \\
\hline \multirow{2}{*}{ TT Cut } & Tt. Cut & Minutes/Day & 30 \\
\hline
\end{tabular}

TABLE II. PARAMETERS OR CONSTANTS USED FOR THE SEWING AREA, AS INPUT IN THE FLOW DIAGRAM OF FIG. 13

\begin{tabular}{|c|l|l|c|}
\hline \multicolumn{2}{|c|}{} & \multicolumn{1}{|c|}{ Unity } & $\begin{array}{l}\text { Modular } \\
\text { Structure }\end{array}$ \\
\hline \multicolumn{2}{|c|}{ Order } & Garment/Order & 5,000 \\
\hline \multicolumn{2}{|c|}{ T. dispon. } & Minutes/Day & 480 \\
\hline \multirow{4}{*}{ TC Sewing } & $\#$ package & Package/Order & 1 \\
\cline { 2 - 4 } & Q. & garment/(package * operators) & 20 \\
\cline { 2 - 4 } & Efc. Sewing & Dmnl & $75 \%$ \\
\cline { 2 - 4 } & Tstd. Sewing & minutes*operators / garment & 5.007 \\
\hline \multirow{3}{*}{ TP Sewing } & Op. Sewing & Operators & 12 \\
\cline { 2 - 4 } & Efp. Sewing & Dmnl & $75 \%$ \\
\hline TT Sewing & Tt. Sewing & Minutes/Day & 35 \\
\hline
\end{tabular}

TABLE III. PARAMETERS OR CONSTANTS USED FOR THE CLEANING AREA, AS INPUT IN THE FLOW DIAGRAM OF FIG. 13

\begin{tabular}{|c|c|c|c|}
\hline & & Unity & $\begin{array}{l}\text { Modular } \\
\text { Structure }\end{array}$ \\
\hline \multicolumn{2}{|c|}{ Order } & Garment/Order & 5,000 \\
\hline \multicolumn{2}{|c|}{ T. dispon. } & Minutes/Day & 480 \\
\hline \multirow{4}{*}{$\begin{array}{l}\text { TC } \\
\text { Cleaning }\end{array}$} & \# package & Package/Order & 1 \\
\hline & Q. & $\begin{array}{l}\text { garment/ (package * } \\
\text { operators) }\end{array}$ & 20 \\
\hline & Efc. Cleaning & Dmnl & $90 \%$ \\
\hline & Tstd Cleaning & minutes*operators / garment & 1.10 \\
\hline \multirow{2}{*}{$\begin{array}{l}\text { TP } \\
\text { Cleaning }\end{array}$} & Op. Cleaning & Operators & 2 \\
\hline & Efp Cleaning & Dmnl & $82 \%$ \\
\hline $\begin{array}{l}\text { TT } \\
\text { Cleaning }\end{array}$ & Tt. Cleaning & Minutes/Day & 40 \\
\hline
\end{tabular}


TABLE IV. PARAMETERS OR CONSTANTS USED FOR THE REVIEW AREA, AS AN ENTRY IN THE FLOW DiagRAM OF FIG. 13

\begin{tabular}{|l|l|l|c|}
\hline \multicolumn{2}{|c|}{} & Unity & $\begin{array}{l}\text { Modular } \\
\text { Structure }\end{array}$ \\
\hline \multicolumn{2}{|c|}{ Order } & Garment/Order & 5,000 \\
\hline \multicolumn{2}{|c|}{ T. dispon. } & Minutes/Day & 480 \\
\hline \multirow{4}{*}{$\begin{array}{l}\text { TC } \\
\text { Review }\end{array}$} & \# package & Package/Order & 1 \\
\cline { 2 - 4 } & Q. & garment/(package * operators) & 20 \\
\cline { 2 - 4 } & Efc. Review & Dmnl & $90 \%$ \\
\cline { 2 - 4 } & Tstd. Review & minutes*operators / garment & 1.03 \\
\hline \multirow{2}{*}{$\begin{array}{l}\text { TP } \\
\text { Review }\end{array}$} & Op. Review & Operators & 2 \\
\cline { 2 - 4 } & Efp. Review & Dmnl & $85 \%$ \\
\hline $\begin{array}{l}\text { TT } \\
\text { Review }\end{array}$ & Tt. Review & Minutes/Day & 30 \\
\hline
\end{tabular}

TABLE V. PARAMETERS OR CONSTANTS USED FOR THE FINISHES AREA, AS INPUT IN THE FLOW DIAGRAM OF FIG. 13

\begin{tabular}{|l|l|l|c|}
\hline \multicolumn{2}{|c|}{} & Unity & $\begin{array}{l}\text { Modular } \\
\text { Structure }\end{array}$ \\
\hline \multicolumn{2}{|c|}{ Order } & Garment/Order & 5,000 \\
\hline \multicolumn{2}{|c|}{ T. dispon. } & Minutes/Day & 480 \\
\hline \multirow{4}{*}{$\begin{array}{l}\text { TC } \\
\text { Finishes }\end{array}$} & \# package & Package/Order & 1 \\
\cline { 2 - 4 } & Q. & garment/ (package * operators) & 20 \\
\cline { 2 - 4 } & Efc Finishes & Dmnl & $80 \%$ \\
\cline { 2 - 4 } & Tstd Finishes & minutes*operators / garment & 1.102 \\
\hline \multirow{2}{*}{\begin{tabular}{l} 
TP Finishes \\
\cline { 2 - 4 }
\end{tabular}} & Op. Finishes & Operators & 2 \\
\cline { 2 - 4 } & Efp Finishes & Dmnl & $88 \%$ \\
\hline
\end{tabular}

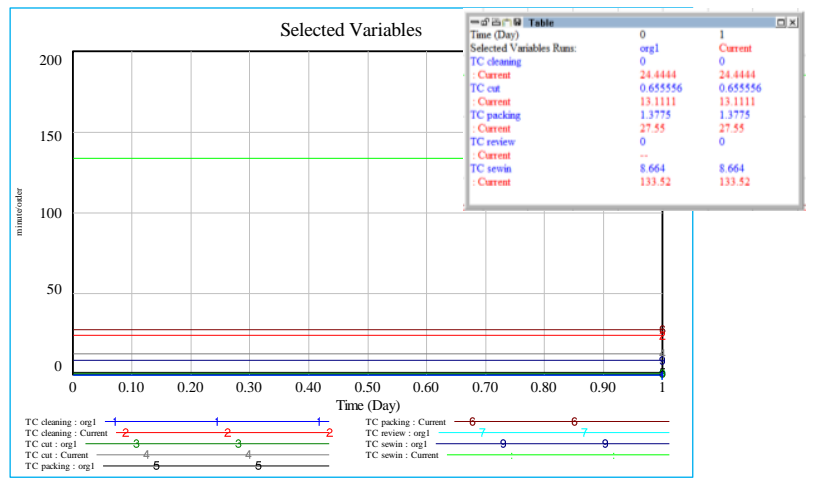

Fig. 17. Behavior of Loading Times with $\mathrm{Q}=20$ Garments / Order and $\mathrm{Q}=1$ Garment / Order.

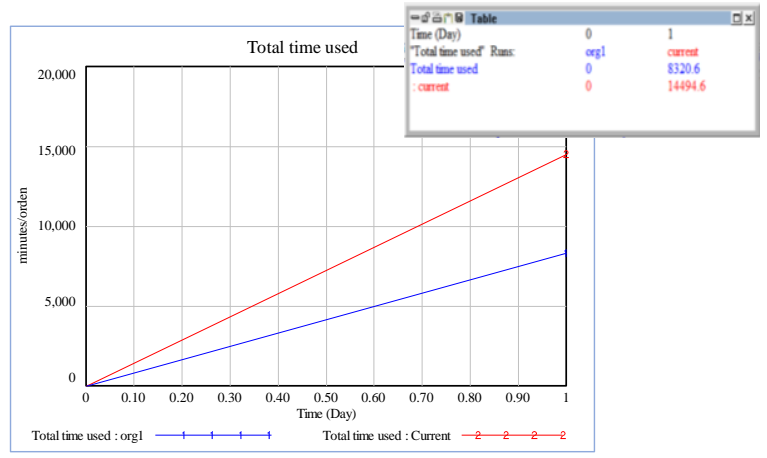

Fig. 18. Behavior of the Total Time used between a Modular Structure vs a Flexible structure.

\section{DISCUSSION}

The development of organizational change was carried out reactively according to the evolution of the international market.

The changes made by the organization to arrive at a flexible structure caused the sewing operating personnel to be reduced by $20 \%$ by own decision.

The personnel only wanted to work piecework with a sewing time without considering the cleaning time and review of their activity, this allowed them to have greater income but affected the changes and the productivity of the company, in such a situation the company had to compensate for this loss of seamstresses with personnel who carried out manual tasks (cleaning and Review) through training in the handling of different types of machines, being considered by the personnel as an added value to their professional career as a technician, increasing their value in the company and their salary.

Alonso [3] points out that organizations exercise subtle mechanisms of domination and control, it is correct, but it was necessary to prevail the sense of authority in a group of people of different types of education, cultures and values in organizational change.

The company developed a training center called "Little School" which allowed to prepare the personnel who performed manual labor in sewing. The trained personnel generated greater involvement in the changes of the organization, which translated into greater productivity and fewer limitations in their performance in the production areas.

What the company did need was a management that would lead the change involving not only administrative but also operational personnel, through successive meetings pointing out the short, medium- and long-term objectives and the positive effects that changes would bring for employers.

The research work carried out by Galvan [1-3] are oriented to the internal analysis of the organization, revealing the level of intrapreneurship, Delgado's study analyzes the organizational structure, human capital and collaboration networks to increase the development of the capacity for innovation and the research carried out by Gonzales statistically concludes that the problems generated by change within an organization are solved through communication. But none of these researchers reveals how the evolution of change in an organization is presented in its organic structure both in the administrative and operational part and how this affects the redesign of the processes in each stage of change, as presented in this research work.

\section{CONClusions}

The company dealt with the problems of change holistically and responding in a systematic, but unplanned way, forming a type of flexible organization for change.

The changes made by the company produced results that allowed it to adapt to the changes in demand requested by clients. Going through five types of transitions or changes, allowed to know the level of commitment and adaptability on the part of the organization, which generated positive results. 
Employee involvement in each stage of change was developed through interactions, training, and knowledge sharing. The management understood that, to make the changes, they should first change their type of leadership from centralist to decentralist, less hierarchical, giving the power of decision (empowerment) to administrative and operational personnel, while still controlling the progress of requests for clients in every operational process.

Each module was considered an agile, dynamic, flexible organization that evolves and generates change through interaction with the client, creating economic and social value in a sustainable way, each order is analyzed, evaluated in quantity, degree of difficulty of the model and availability of resources, establishing processing times and delivery dates.

The result obtained as a result of the research allowed to know the degree of evolution of each stage of change within a manufacturing organization, developing and analyzing the levels of behavior in a quantitative and graphical way at each stage of the change through scenario models and algorithms and their interrelation in the use of productive resources as dependent variables of the system.

For future work, the incidence of dynamic organizational change will be expanded with the concepts of chaos, as Pacheco [25] points out, learning is connected and weaves growing interactive networks of progressive complexity. And complex systems or sciences of complexities [26] where adaptive, non-linear systems will be analyzed taking as references Edward Lorenz and Benoit Mandelbrot. The main asset of an organization is the person and as such their degree of knowledge differ, this knowledge is found in their brain which is a non-linear product of a non-linear evolution.

\section{REFERENCES}

[1] M. Chudnovsky, M. Cafarelli, Changes in ihe Organizational Structures of the State And their Link to the Composition of Public Employment. Argentina 2003-2016, Foro Internacional (FI) 232, LVIII, 2018 (2), p. 281.

[2] G. Millan, R. Diaz, M. Gonzales, Oscar U., Cambio Organizacional en las Medianas y Grandes Empresas del Valle de SugamuxI, Dimensión Empresarial 15(1) 2016,p. 210.

[3] E. Galvan y M. Sanchez, Factores organizacionales relacionados con el comportamiento intraemprendedor, Innovar vol. 29, No 71 2019, p. 61.

[4] A. Delgado, E. Vargas, F, Rodriguez y J. Monets, Organizational Structure, Human Capital and Collaboration Networks: Determinants of Innovation Capability in Restaurants, Ad-Minister No 32, 2018, p. 12.

[5] A. Segredo, Theoretical approach to the evolution, theories, criteria and characteristics supporting the development of organizations, Revista Cubana de Salud Pública 2016, p. 588.

[6] C. Reis, L. Benvenutti, L. Campos, M. Uriona, The Influence of Company Size on Energy Management Systems Adoption: A System Dynamics Model, Brazilian Business Review 2020, p. 584.

[7] J. Calpa, Validation of a Model of Reverse Logistics for the recovery of WEEE from the city of Cali, based on the Systemic Thinking using a simulation of System Dynamics, Tecnologicas vol. 23, $\mathrm{N}^{\circ} 48,2020$, p. 66.
[8] L. Rodriguez, J. Loyo, M. Lopez, J. Gonzales, Dynamic simulation of a back-feeded production system, II Ingenieria Industrial vol. XL, $\mathrm{N}^{\circ} 2$, 2019, p. 172.

[9] D. Zapata y J. Oviedo, Modelo de Simulación de Alternativas de Productividad para Apoyar los Procesos de Toma de Decisiones en Empresas del Sector Floricultor Antioqueño, Información Tecnológica 2019, p. 58.

[10] Y. Palmas, A. Franco, L. Lopez, C. Giraldo, Sistemas complejos y turismo: aplicación del modelo de turismo armónico en dos localidades de países latinoamericanos, Cuadernos de Geografia vol. 29, $\mathrm{N}^{\circ} 2,2020$, p. 356.

[11] G. Becerra, Complex Systems Theory and Social Systems Theory in the controversies of complexity, Convergencia e-ISSN 2448-5799, vol. 27, 2020, p. 5.

[12] L. Rodriguez, Contribución a la crítica de la teoría de los sistemas complejos: bases para un programa de investigaciónp. Estudios Sosiologicos, DOI: 10.24201, vol. $36 \mathrm{~N}^{\circ} 106,2018$, p. 76.

[13] Z. Yang, Z. Ge, Monitoring and prediction of big process data with deep latent variable models and parallel computing, Journal of Process Control, 2020, p. 19.

[14] D. Van, M. Mandegari, S. Farzad, J. Gorgens, Techno-economic and environmental analysis of bio-oil production from forest residues via non-catalytic and catalytic pyrolysis processes, Energy Conversion and Management 213 (2020) 112815, p. 3.

[15] W. Tupia, L. Brañez, A. Arribasplata, J. Acosta, An experimental methodology to determine the parameters of the compression molding process of composite materials made of recycled thermoplastic and recovered wood, Revista Materia vol. 23, $\mathrm{N}^{\circ} 3,2020$, p. 2.

[16] J. Vargas, F. Jimenez, J. Toro, Y. Rodriguez, Comparing Push and Pull Manufacturing Systems via Simulation, Ciencia e Ingeneiria Neogranadina 2019, p. 84.

[17] F. Ferreiro, M. Del Campo. M. Santos, Training and talent management of the most valued human resources companies in Spain, Contaduría y Administración 64 (3), 2019, p. 5.

[18] E. Arvizu, L. Velasquez, Corporate social responsibility: Distinctive, practices and processes of the mining sector in Sonora, Mexico, Revista de Alimentación Contemporánea y Desarrollo Regional Volumen 29, Número 54, 2019, p. 5.

[19] J. Gray, M. Minsky, Models in Simulation, Softw Syst. Model 2016, p. 605.

[20] J. Gonzales, M. Rodriguez y O. Gonzales, Organizational Change In Medium And Large Companies Of Sugamuxi Valley, Dimension Empresarial vol. 15, No 1, 2017, p. 210.

[21] G. Ponce, D. Espinoza, J. Zamura y K. Tapia, Organizational capacities to generate value: analysis of industrial sector, Retos vol. 7 No 13, 2017, p. 144.

[22] H. Aray, Effects of decentralization on public infrastructure accumulation: The case of Spain, El trimestre económico vol. 85, No 340, 2018, p. 862.

[23] S. Vasquez, C. Lujan, J. Olivas, H. Gonzales y H. Lujas, Prospective of forest sector's organizational system in Chihuahua, Mexico, Madera y Bosquez vol. 23, No 2, 2017, p. 220.

[24] L. Rodriguez, J. Loyo, M. Lopez, J. Gonzales, Simulación dinámica de un sistema de producción retroalimentado, Ingeniería Industrial 2019, p. 173.

[25] P. Pacheco, Study of a learning process in experimental sciences by the Chaos Theory, Formación Universitaria vol. $13 \mathrm{~N}^{\circ} 3,2020$, p. 78.

[26] G. Becerra, Complex Systems Theory and Social Systems Theory in the controversies of complexity, Convergencia vol.27, 2020, p. 2. 